\title{
Análise econômica da produção de feijão em função de doses de nitrogênio e coberturas vegetais ${ }^{1}$
}

\author{
Gustavo Antonio Xavier Gerlach², Orivaldo Arf², \\ Daiene Camila Dias Chaves Corsini ${ }^{2}$, Juliano Costa da Silva ${ }^{2}$, Admar Júnior Coletti ${ }^{2}$
}

\begin{abstract}
Economic analysis of bean yield

according to nitrogen levels and cover crops

Nitrogen is the nutrient applied in greater amounts in bean crops, the most limiting to the growth and development of bean plants and the most onerous to its production cost. A good option for producers to reduce costs, concerning nitrogen fertilizers, is the use of ground cover plants, also known as green manures. So, this study aimed at evaluating the production costs and profitability rates of different treatments involving cover crops and topdressing nitrogen doses, in irrigated no-tillage bean crops, in the winter of 2010 and 2011. The experiment was conducted in an experimental area, in Selvíria, Mato Grosso do Sul State, Brazil, in a typical Oxisol. The treatments consisted of six cover crops (Crotalaria juncea, millet, pigeon pea, Crotalaria juncea + millet, pigeon pea + millet and fallow ground), and four nitrogen doses $\left(0 \mathrm{~kg} \mathrm{ha}^{-1}, 30 \mathrm{~kg} \mathrm{ha}^{-1}, 60 \mathrm{~kg} \mathrm{ha}^{-1}\right.$ and $\left.90 \mathrm{~kg} \mathrm{ha}^{-1}\right)$. The total operating cost, gross revenue, operating profit, profitability index and equilibrium productivity and price were evaluated. It was concluded that the use of Crotalaria juncea as a ground cover crop resulted in the highest values for total operating cost and operating profit and the highest profitability indexes, and that increased nitrogen levels also increased the total operating cost, with an increasing trend for productivity and, consequently, for the equilibrium price.
\end{abstract}

KEY-WORDS: Phaseolus vulgaris L.; no-tillage system; production costs; profitability index.

\section{INTRODUÇÃO}

A cultura do feijão (Phaseolus vulgaris L.) constitui-se em uma das mais importantes explorações agrícolas do Brasil, não só pela área cultivada e pelo valor da produção, mas, também, por ser considerada a principal fonte de proteínas, para as camadas da população de menor poder aquisitivo (Soratto 2002).

\section{RESUMO}

O nitrogênio é o nutriente aplicado em maior quantidade à cultura do feijão, o mais limitante ao crescimento e desenvolvimento das plantas e o que mais onera o custo de produção. Uma boa opção para o produtor diminuir custos, com a utilização de fertilizantes nitrogenados, é a utilização de plantas de cobertura do solo, também conhecidas como adubos verdes. Assim, este trabalho objetivou avaliar os custos de produção e índices de lucratividade de diferentes tratamentos envolvendo coberturas vegetais e doses de nitrogênio em cobertura, na cultura do feijoeiro irrigado, em sistema plantio direto, nas safras de inverno de 2010 e 2011. O trabalho foi realizado em área experimental localizada no município de Selvíria (MS), em Latossolo Vermelho distrófico típico. Os tratamentos constituíram-se de seis coberturas vegetais (Crotalaria juncea, milheto, guandú, Crotalaria juncea + milheto, guandú + milheto e pousio) e quatro doses de $\mathrm{N}\left(0 \mathrm{~kg} \mathrm{ha}^{-1}, 30 \mathrm{~kg} \mathrm{ha}^{-1}, 60 \mathrm{~kg} \mathrm{ha}^{-1} \mathrm{e}\right.$ $\left.90 \mathrm{~kg} \mathrm{ha}^{-1}\right)$. Foram estimados o custo operacional total, receita bruta, lucro operacional, índice de lucratividade, produtividade de equilíbrio e o preço de equilíbrio. Concluiu-se que o uso da Crotalaria juncea, como cobertura vegetal do solo, proporcionou os maiores valores de custo operacional total e lucro operacional e os melhores índices de lucratividade, e que o incremento nas doses de nitrogênio aumentou o custo operacional total, com tendência de aumento na produtividade e, consequentemente, no preço de equilíbrio.

PALAVRAS-CHAVE: Phaseolus vulgaris L.; plantio direto; custos de produção; índices de lucratividade.

Tendo-se em vista a sua importância, em âmbito nacional, faz-se necessário o conhecimento sobre as práticas de adubação adotadas por produtores, as quais, juntamente com outras práticas culturais, como a irrigação e os tratamentos fitossanitários, contribuem para o aumento da produtividade e do custo de produção das culturas agrícolas.

De acordo com Malavolta (1979), o nitrogênio $(\mathrm{N})$ é um dos nutrientes mais absorvidos pelo

1. Trabalho recebido em out./2012 e aceito para publicação em mar./2013 ( $\mathrm{n}^{\circ}$ registro: PAT 20537).

2. Universidade Estadual Paulista (Unesp), Departamento de Fitotecnia, Tecnologia de Alimentos e Socioeconomia, Ilha Solteira, SP, Brasil.E-mails: gustavo71180@aluno.feis.unesp.br, arf@agr.feis.unesp.br, daiene6@hotmail.com, jcsagro@yahoo.com.br, admarcoletti@yahoo.com.br. 
feijoeiro e, quando aplicado na dose recomendada, promove rápido crescimento, aumento da área foliar e do teor de proteína nas sementes e alimenta os micro-organismos do solo, que decompõem a matéria orgânica, além de aumentar o teor de matéria seca.

Para a obtenção de altas produtividades, a curto e longo prazo, é importante o emprego de tecnologias sustentáveis, como o plantio direto. Entretanto, segundo Lemos et al. (2008), neste sistema, pode ser necessário utilizar maiores quantidades de $\mathrm{N}$, em função do processo de imobilização dos nutrientes, pelos micro-organismos que decompõem a palhada, promovendo competição com o feijoeiro, principalmente nos estádios iniciais de desenvolvimento da palha, limitando, assim, a produtividade da cultura.

O nitrogênio é o nutriente aplicado em maior quantidade na cultura do feijão, o mais limitante ao crescimento e desenvolvimento da planta e o que mais onera o seu custo de produção (Amado et al. 2002). Assim, estudos que possam contribuir para uma indicação mais eficiente, do ponto de vista agroeconômico, com relação à escolha da espécie de adubo verde, bem como seu sistema de produção e a quantidade de N, são de grande valia para o produtor.

Informações sobre os custos de uma cultura são de fundamental importância para o agricultor, pois auxiliam na combinação dos recursos utilizados em sua produção, visando à obtenção de melhores resultados (Crepaldi 1998).

Diante do exposto, este trabalho objetivou avaliar o custo de produção e os índices de lucratividade de diferentes tratamentos envolvendo coberturas vegetais e doses de nitrogênio em cobertura, na cultura do feijoeiro irrigado, em sistema plantio direto.

\section{MATERIAL E MÉTODOS}

O estudo foi conduzido em área experimental localizada no município de Selvíria (MS) $\left(20^{\circ} 22^{\prime} \mathrm{S}\right.$, $51^{\circ} 22^{\prime} \mathrm{W}$ e altitude de $335 \mathrm{~m}$ ). O solo é classificado como Latossolo Vermelho distrófico típico, textura argilosa (Embrapa 2006), o qual foi, originalmente, ocupado por vegetação de Cerrado e cultivado com culturas anuais, há mais de 25 anos. A classificação climática da região, segundo Köppen, é Aw, definida como tropical úmida, com estação chuvosa no verão e seca no inverno. A temperatura média anual é de $23,5^{\circ} \mathrm{C}$, a precipitação pluvial média anual de $1.370 \mathrm{~mm}$ e a umidade relativa do ar média anual de $70 \%$ a $80 \%$.
O delineamento experimental utilizado foi o de blocos casualizados, dispostos em esquema fatorial $6 \times 4$, com quatro repetições, sendo constituídos por seis coberturas vegetais anteriores ao feijoeiro (Crotalaria juncea L.; milheto - Pensetum glaucum (L.) R. Br.; guandú - Cajanus cajan (L.) Millsp; Crotalaria juncea + milheto; guandú + milheto; e pousio) e quatro doses de $\mathrm{N}$ em cobertura do feijoeiro ( $\left.0 \mathrm{~kg} \mathrm{ha}^{-1}, 30 \mathrm{~kg} \mathrm{ha}^{-1}, 60 \mathrm{~kg} \mathrm{ha}^{-1} \mathrm{e} 90 \mathrm{~kg} \mathrm{ha}^{-1}\right)$. As parcelas foram constituídas de sete linhas de $6,0 \mathrm{~m}$ de comprimento, espaçadas em $0,45 \mathrm{~m}$, e 13 sementes por metro, para os dois anos de cultivo (2010 e 2011). Na semeadura das coberturas vegetais, foi utilizada, para os tratamentos com guandú, densidade de semeadura de $15 \mathrm{~kg} \mathrm{ha}^{-1} \mathrm{e}$, para as demais, $40 \mathrm{~kg} \mathrm{ha}^{-1}$ de sementes.

O experimento foi conduzido durante as safras de inverno de 2010 e 2011, em sistema plantio direto, em área anteriormente ocupada com a cultura do arroz. As coberturas vegetais foram semeadas no mês de fevereiro de cada ano e a dessecação das coberturas vegetais foi feita com o herbicida gliphosate $\left(1.920\right.$ g do i.a. ha $\left.{ }^{-1}\right)+2,4 \mathrm{D}\left(1.209 \mathrm{~g}\right.$ do i.a. ha $\left.{ }^{-1}\right)$, aos 90 dias após a semeadura das coberturas vegetais.

Após dois dias da aplicação do herbicida, a área foi manejada com desintegrador mecânico (Triton), para facilitar a semeadura. A cultivar de feijão utilizada foi a Pérola, que possui grãos do tipo carioca. As sementes foram tratadas com fungicida carbendazim + tiram $\left(45+105\right.$ g do i.a. ha $\left.{ }^{-1}\right)$ e a semeadura foi realizada mecanicamente, nos dias $03 \mathrm{e}$ 07 de maio de 2010 e 2011, respectivamente.

Antes da instalação dos experimentos, o solo do local foi amostrado, na camada de $0,0-0,20 \mathrm{~m}$, e os resultados da análise de fertilidade do solo (Raij \& Quaggio 1983) foram os seguintes: $\mathrm{P}$ (resina) $=17,0 \mathrm{mg} \mathrm{dm}^{-3}$; M.O. $=13,0 \mathrm{~g} \mathrm{dm}^{-3} ; \mathrm{pH}\left(\mathrm{CaCl}_{2}\right)=5,2 ; \mathrm{K}=2,9 \mathrm{mmol}_{\mathrm{c}} \mathrm{dm}^{-3}$; $\mathrm{Ca}=33,0 \mathrm{mmol}_{\mathrm{c}} \mathrm{dm}^{-3} ; \mathrm{Mg}=14,0 \mathrm{mmol}_{\mathrm{c}} \mathrm{dm}^{-3}$; $\mathrm{H}+\mathrm{Al}=27,0 \mathrm{mmol}_{\mathrm{c}} \mathrm{dm}^{-3} ; \mathrm{Al}=0,0 \mathrm{mmol}_{\mathrm{c}} \mathrm{dm}^{-3}$; $\mathrm{SB}=50,0 \mathrm{mmol}_{\mathrm{c}} \mathrm{dm}^{-3}$; CTC $=77,0 \mathrm{mmol}_{\mathrm{c}} \mathrm{dm}^{-3}$; e $\mathrm{V}=65 \%$. Com base nestas características químicas do solo e na tabela de recomendação de adubação para a cultura do feijoeiro, para o Estado de São Paulo (Cantarella et al. 1997), calculou-se a adubação química básica no sulco de semeadura, constante para todos os tratamentos, que foi de $250 \mathrm{~kg} \mathrm{ha}^{-1}$ da fórmula $08-28$ 16. A adubação nitrogenada de cobertura foi efetuada no estádio fenológico $\mathrm{V}_{4-4}$ (Ambrosano et al. 1996), aplicando-se o adubo na entrelinha, a uma distância de $0,20 \mathrm{~m}$ da linha da cultura. 
As operações mecanizadas foram executadas com trator de $75 \mathrm{cv}$ de potência, pulverizador de barras de 14,0 m, desintegrador mecânico com 2,3 m de largura e semeadora de grãos finos de sete linhas, com 0,34 m de espaçamento. A semeadura do feijão foi realizada com trator de $100 \mathrm{cv}$ de potência, semeadora a vácuo de sete linhas (espaçadas em $0,45 \mathrm{~m}$ ) e adubador a lanço com faixa de $18,0 \mathrm{~m}$. Já para a colheita, utilizou-se uma recolhedora batedora de feijão.

O manejo de plantas daninhas foi efetuado com uma única aplicação do herbicida fluazifop-p-butil + fomesafen $\left(160+200 \mathrm{~g}\right.$ do i.a. ha $\left.{ }^{-1}\right)$, em pós-emergência, e o controle de pragas com quatro aplicações do inseticida methamidophos (600 g do i.a. ha $\left.{ }^{-1}\right)$. O controle de doenças foi realizado com duas aplicações do fungicida azoxistrobina (60 $\mathrm{g}$ do i.a. ha $\left.{ }^{-1}\right) \mathrm{e}$ o fornecimento de água foi efetuado, quando necessário, por um sistema fixo de irrigação, do tipo pivô central. As colheitas do feijão foram realizadas em agosto de 2010 e 2011.

Para o cálculo do custo de produção, foi utilizada a estrutura do custo operacional total de produção, adotada pelo Instituto de Economia Agrícola (IEA) e proposta por Martin et al. (1998). O custo operacional efetivo (COE) foi composto pelas despesas com operações mecanizadas (incluindo depreciações), operações manuais e materiais consumidos. Se forem acrescentadas ao $\mathrm{COE}$ as despesas com os juros de custeio e outras despesas, têm-se o custo operacional total (COT).

Os custos foram obtidos com base nos seguintes itens: a) para as operações manuais, foi realizado um levantamento das necessidades de mão de obra, nas diversas fases do ciclo produtivo do feijão, relacionando, para cada operação, o número de homens/ dia (HD) para executá-la, e, em seguida, multiplicado o coeficiente técnico de mão de obra pelo valor médio pago na região; b) os gastos com materiais foram obtidos mediante o produto entre a quantidade dos materiais utilizados e os seus respectivos preços de mercado; c) para outras despesas, considerou-se a taxa de $5 \%$ do total das despesas com o COE; d) os juros de custeio foram obtidos considerando-se a taxa de $6,75 \%$ a.a. (taxa de juros utilizada em operações de crédito rural) sobre $50 \%$ do COE; e) a depreciação dos bens de capital fixo foi calculada pelo método linear: Depreciação $=($ valor inicial do bem - valor final)/vida útil.

Para determinar a lucratividade dos tratamentos envolvidos, foram calculados os seguintes itens
(Martin et al. 1998): a) receita bruta (RB), em R\$, obtida entre a quantidade produzida (em número de sacos de $60 \mathrm{~kg}$ ) e o preço médio recebido pelo produtor, em $\mathrm{R} \$ \mathrm{RB}=$ quantidade produzida $\mathrm{x}$ preço por unidade; b) lucro operacional (LO), como a diferença entre a receita bruta e o custo operacional total: $\mathrm{LO}=$ RB - COT; c) índice de lucratividade (IL), entendido como a proporção da receita bruta que se constitui em recursos disponíveis, após a cobertura do custo operacional total de produção: $\mathrm{IL}=(\mathrm{LO} / \mathrm{RB}) \times 100$; d) preço de equilíbrio (PE), dado, em determinado nível de custo operacional total de produção, como o preço mínimo necessário a ser obtido para cobrir o COT, considerando-se a produtividade média obtida pelo produtor: $\mathrm{PE}=\mathrm{COT} /$ produtividade média obtida pelo produtor; e) produtividade de equilíbrio (ProE), dada, em determinado nível de custo operacional total de produção, como a produtividade mínima necessária para cobrir o COT, considerando-se o preço médio recebido pelo produtor: $\mathrm{ProE}=\mathrm{COT} /$ preço médio recebido pelo produtor.

Para fins de análise econômica, cada tratamento foi considerado como uma lavoura comercial, sendo utilizado o mesmo espaçamento para todos os tratamentos, variando-se apenas as coberturas vegetais e as doses da adubação nitrogenada. Os coeficientes técnicos das operações, isto é, o tempo necessário para realizá-las por unidade de área e outras informações técnicas, foram levantados com o auxílio de técnicos com experiência na cultura, na região.

Os valores de produtividade dos tratamentos foram convertidos em sacos (sc) de $60 \mathrm{~kg}$ de grãos, que é a forma tradicional de comercialização, pelos produtores da região. Os valores pagos pelos insumos foram atualizados para os meses de agosto de $2010 \mathrm{e}$ 2011, para as safras de 2010 e 2011, respectivamente. Os preços recebidos pelos produtores, nos últimos cinco anos, foram os seguintes: $\mathrm{R} \$ 55,86$ (agosto de 2006), R \$ 85,25 (agosto de 2007), R \$ 163,44 (agosto de 2008), R $\$ 76,00$ (agosto de 2009), R \$ 95,53 (agosto de 2010) e R $\$ 102,94$ (agosto de 2011) (IEA 2012).

Neste trabalho, considerou-se o preço médio dos últimos 5 anos recebido pelos produtores, sendo de $\mathrm{R} \$ 95,53$, para a safra de 2010 , e de $\mathrm{R} \$ 102,94$, para a safra de 2011. Estes preços médios foram indexados pelo Índice Geral de Preços - Disponibilidade Interna (IGP-DI), publicado pela Fundação Getúlio Vargas (2012), para os meses de agosto de 2010 e 2011, e corresponderam a $\mathrm{R} \$ 113,17$ e $\mathrm{R} \$ 118,52$, respectivamente. 


\section{RESULTADOS E DISCUSSÃO}

Na Tabela 1, encontra-se a estimativa do custo operacional total obtido com a cultura do feijão "de inverno" irrigado, com cobertura de Crotalaria juncea e dose de $90 \mathrm{~kg} \mathrm{ha}^{-1}$ de nitrogênio (safra de 2010), no município de Selvíria (MS). Este modelo de estrutura de COT foi utilizado individualmente para todos os tratamentos, embora, na Tabela 1, esteja representado apenas um dos tratamentos estudados.

Verificou-se que os gastos com insumos e operações mecanizadas foram os mais elevados $(31,20 \%$ e $24,47 \%$, respectivamente). Os custos com operações manuais e irrigação corresponderam a $14,68 \%$ e $15,85 \%$ do COT, respectivamente. Quanto aos materiais utilizados, os maiores gastos foram atribuídos aos defensivos, seguidos por fertilizantes e sementes (13\%, 10\% e 9\%, respectivamente).

No cálculo do COT, para os diferentes tratamentos, a adubação nitrogenada contribuiu, nas doses de $0 \mathrm{~kg} \mathrm{ha}^{-1}, 30 \mathrm{~kg} \mathrm{ha}^{-1}, 60 \mathrm{~kg} \mathrm{ha}^{-1}$ e $90 \mathrm{~kg} \mathrm{ha}^{-1}$, com $0 \%, 5 \%, 9 \%$ e $14 \%$, respectivamente, e as coberturas vegetais Crotalaria juncea, milheto, guandú, Crotalaria juncea + milheto, guandú + milheto e pousio com $14 \%, 2,5 \%, 2,5 \%, 8 \%, 2,6 \%$ e $0 \%$, respectivamente. O COT obtido nos tratamentos

Tabela 1. Estimativa do custo operacional e percentagem de cada custo obtido com a cultura do feijão "de inverno" irrigado, com cobertura vegetal e dose de $90 \mathrm{~kg} \mathrm{ha}^{-1}$ de nitrogênio (Selvíria, MS, safra 2010).

\begin{tabular}{|c|c|c|c|c|c|}
\hline Descrição & Especificação & Valor unitário & Quantidade & Total $(\mathrm{R} \$)$ & Percentagem \\
\hline \multicolumn{6}{|l|}{ A. Operações mecanizadas } \\
\hline \multicolumn{6}{|l|}{ Anterior ao feijão } \\
\hline Semeadura crotalária & HM & 39,53 & 0,99 & 39,14 & 1,44 \\
\hline Dessecação & $\mathrm{HM}$ & 39,53 & 0,40 & 15,81 & 0,58 \\
\hline Uniformização & HM & 39,53 & 1,18 & 46,51 & 1,71 \\
\hline \multicolumn{6}{|l|}{ Implantação do feijão } \\
\hline Semeadura do feijão & HM & 51,26 & 0,63 & 32,44 & 1,19 \\
\hline Aplicação cobertura & HM & 39,53 & 0,24 & 9,41 & 0,35 \\
\hline \multicolumn{6}{|l|}{ Tratos culturais } \\
\hline Pulverização (4x) & HM & 39,53 & 0,40 & 63,25 & 2,32 \\
\hline Irrigação & $\mathrm{R} \$ \mathrm{~mm}^{-1}$ & 2,88 & 150,00 & 432,00 & 15,85 \\
\hline Colheita & HM & 39,53 & 0,71 & 28,24 & 1,04 \\
\hline Subtotal A & & & & 666,80 & 24,47 \\
\hline \multicolumn{6}{|l|}{ B - Operações manuais } \\
\hline Arranquio & HD & 40,00 & 4,00 & 160,00 & 5,87 \\
\hline Ensacamento & HD & 40,00 & 2,00 & 80,00 & 2,94 \\
\hline Carregamento & HD & 40,00 & 4,00 & 160,00 & 5,87 \\
\hline Subtotal B & & & & 400,00 & 14,68 \\
\hline \multicolumn{6}{|l|}{ C - Material } \\
\hline Semente de feijão & $\mathrm{kg}$ & 3,00 & 90,00 & 270,00 & 9,91 \\
\hline Adubo semeadura 08-28-16 & $\mathrm{t}$ & 900,00 & 0,25 & 225,00 & 8,26 \\
\hline Derosal & $\mathrm{L}$ & 37,02 & 0,25 & 9,26 & 0,34 \\
\hline DMA 806 & $\mathrm{~L}$ & 8,58 & 1,50 & 12,87 & 0,47 \\
\hline Gliz 480 & $\mathrm{~L}$ & 7,78 & 4,00 & 31,12 & 1,14 \\
\hline Robust & $\mathrm{L}$ & 125,00 & 0,80 & 100,00 & 3,67 \\
\hline Amistar & $\mathrm{kg}$ & 525,00 & 0,24 & 126,00 & 4,62 \\
\hline Tamaron $(4 \mathrm{x})$ & $\mathrm{L}$ & 19,00 & 4,00 & 76,00 & 2,79 \\
\hline Subtotal C & & & & 850,25 & 31,20 \\
\hline \multicolumn{6}{|l|}{ D - Tratamento } \\
\hline Crotalaria juncea & $\mathrm{kg}$ & 8,00 & 40,00 & 320,00 & 11,74 \\
\hline Dose de N & $\mathrm{t}$ & $1.270,86$ & 0,20 & 254,17 & 9,33 \\
\hline Subtotal D & & & & 574,17 & 21,07 \\
\hline Custo operacional efetivo (COE) & & & 2.49 & & 91,43 \\
\hline Outras despesas (5\% do COE) & & & & & 4,57 \\
\hline Juros de custeio & & & & & 4,00 \\
\hline Custo operacional total (COT) & & & 2.72 & & 100,00 \\
\hline
\end{tabular}


com Crotalaria juncea pode ser justificado pelos altos preços das sementes (Tabela 2), que, devido à alta procura para reforma de canaviais, fez com que os preços de comercialização aumentassem. Em seguida, vieram os tratamentos Crotalaria juncea + milheto, milheto, guandú, guandú + milheto e pousio.

Dentre os tratamentos testados, o pousio apresentou o menor COT, devido à inexistência da implantação de cobertura do solo, ou seja, eliminou-se uma operação de semeadura e, também, o gasto com sementes.

Comparando-se as duas safras (2010 e 2011), notou-se que a sucessão Crotalaria juncea:feijoeiro, comparada ao feijoeiro implantado em área de pousio, apresentou aumento de, aproximadamente, $18 \%$ no COT, seguida da sucessão Crotalaraia juncea + milheto:feijoeiro, com aumento de cerca de $12 \%$. Este acréscimo é justificado pelo gasto com sementes de Crotalaria juncea $\left(\mathrm{R} \$ 8,00 \mathrm{~kg}^{-1}\right)$, cujo preço foi muito superior ao do guandú $\left(\mathrm{R} \$ 3,80 \mathrm{~kg}^{-1}\right)$ e do milheto $\left(\mathrm{R} \$ 1,40 \mathrm{~kg}^{-1}\right)$.

Tabela 2. Custo operacional total (COT) obtido com a cultura do feijão irrigado, em função de coberturas vegetais e doses de nitrogênio (Selvíria, MS, safras de 2010 e 2011).

\begin{tabular}{|c|c|c|c|}
\hline \multirow[t]{2}{*}{ Cobertura vegetal } & \multirow{2}{*}{$\begin{array}{l}\text { Doses de } \\
\text { Nitrogênio } \\
\left(\mathrm{kg} \mathrm{h}^{-1}\right)\end{array}$} & \multicolumn{2}{|c|}{$\begin{array}{c}\text { Custo operacional } \\
\text { total }(\mathrm{R} \$)\end{array}$} \\
\hline & & 2010 & 2011 \\
\hline \multirow{4}{*}{ Crotalaria juncea } & 0 & $2.446,76$ & $2.501,45$ \\
\hline & 30 & $2.544,06$ & $2.613,90$ \\
\hline & 60 & $2.631,63$ & $2.715,10$ \\
\hline & 90 & $2.724,76$ & $2.822,72$ \\
\hline \multirow{4}{*}{ Milheto } & 0 & $2.158,01$ & $2.212,70$ \\
\hline & 30 & $2.255,31$ & $2.325,15$ \\
\hline & 60 & $2.342,88$ & $2.426,35$ \\
\hline & 90 & $2.436,01$ & $2.533,97$ \\
\hline \multirow{4}{*}{ Guandú } & 0 & $2.159,11$ & $2.213,79$ \\
\hline & 30 & $2.256,41$ & $2.326,24$ \\
\hline & 60 & $2.343,98$ & $2.427,44$ \\
\hline & 90 & $2.437,11$ & $2.535,07$ \\
\hline \multirow{4}{*}{$\begin{array}{l}\text { Crotalaria juncea }+ \\
\text { milheto }\end{array}$} & 0 & $2.302,39$ & $2.357,08$ \\
\hline & 30 & $2.399,69$ & $2.469,52$ \\
\hline & 60 & $2.487,26$ & $2.570,72$ \\
\hline & 90 & $2.580,39$ & $2.678,35$ \\
\hline \multirow{4}{*}{ Guandú + milheto } & 0 & $2.210,51$ & $2.265,20$ \\
\hline & 30 & $2.307,81$ & $2.377,65$ \\
\hline & 60 & $2.395,38$ & $2.478,85$ \\
\hline & 90 & $2.488,51$ & $2.586,47$ \\
\hline \multirow{4}{*}{ Pousio } & 0 & $2.053,95$ & $2.108,64$ \\
\hline & 30 & $2.151,26$ & $2.221,09$ \\
\hline & 60 & $2.238,83$ & $2.322,29$ \\
\hline & 90 & $2.331,96$ & $2.429,92$ \\
\hline
\end{tabular}

Pesquisas realizadas por Bordin et al. (2003) destacaram que, na sucessão de feijão a leguminosas, são proporcionadas maiores produtividades, com menores doses de adubação nitrogenada, constatação também confirmada por Andrioli et al. (2008).

Quanto à produtividade de grãos, observou-se que, nos dois anos agrícolas, o plantio de Crotalaria juncea, antecedendo o feijoeiro, apresentou a maior produtividade, evidenciando os seus benefícios como cobertura do solo (Tabela 3 ).

Verificou-se que, com o aumento da adubação nitrogenada, houve tendência ao aumento na produtividade, porém, não houve significância, pelo teste estatístico utilizado. Arf et al. (1999) também verificaram maior produtividade do feijoeiro em sucessão a leguminosas, em comparação ao cultivo após gramíneas.

As maiores produtividades foram observadas com cultivo anterior de leguminosas e este efeito é relacionado com a menor relação $\mathrm{C} / \mathrm{N}$, nos restos destas culturas, ocorrendo disponibilização mais rápida do $\mathrm{N}$, coincidindo, assim, com o período de exigência da cultura (Oliveira et al. 2002).

Mantendo-se constante o preço do feijão, em cada ano agrícola, as receitas brutas dos tratamentos seguiram a mesma tendência das produtividades (Tabela 4).

Tabela 3. Valores médios da produtividade de grãos de feijão, em função de coberturas vegetais e doses de nitrogênio em cobertura (Selvíria, MS, 2010/2011).

\begin{tabular}{|c|c|c|}
\hline \multirow{2}{*}{ Tratamentos } & \multicolumn{2}{|c|}{ Produtividade $\left(\mathrm{kg} \mathrm{ha}^{-1}\right)$} \\
\hline & 2010 & 2011 \\
\hline \multicolumn{3}{|c|}{ Coberturas do solo } \\
\hline Crotalaria juncea & $2.076 \mathrm{a}$ & $2.261 \mathrm{a}$ \\
\hline Milheto & $1.774 \mathrm{~b}$ & $1.907 \mathrm{ab}$ \\
\hline Guandú & $1.916 \mathrm{ab}$ & $1.630 \mathrm{~b}$ \\
\hline Crotalaria juncea + milheto & $2.005 \mathrm{ab}$ & $1.760 \mathrm{~b}$ \\
\hline Guandú + milheto & $1.843 \mathrm{ab}$ & $1.907 \mathrm{ab}$ \\
\hline Pousio & $1.854 \mathrm{ab}$ & $1.771 \mathrm{~b}$ \\
\hline \multicolumn{3}{|c|}{ Doses de nitrogênio $\left(\mathrm{kg} h^{-1}\right)$} \\
\hline 0 & 1.881 & 1.700 \\
\hline 30 & 1.847 & 1.853 \\
\hline 60 & 1.950 & 1.984 \\
\hline 90 & 1.967 & 1.956 \\
\hline $\mathrm{C}$ (coberturas vegetais) & $3,65 *$ & $4,65^{*}$ \\
\hline $\mathrm{D}($ doses de $\mathrm{N})$ & $1,40^{\mathrm{ns}}$ & $2,44^{\mathrm{ns}}$ \\
\hline $\mathrm{CX} D$ & $0,81^{\text {ns }}$ & $1,72^{\text {ns }}$ \\
\hline DMS & 242,73 & 416,93 \\
\hline C.V. $(\%)$ & 12,25 & 21,47 \\
\hline
\end{tabular}


Tabela 4. Produtividade e receita bruta obtidas com a cultura do feijão irrigado, em função de coberturas vegetais e doses de nitrogênio (Selvíria, MS, safras de 2010 e 2011).

\begin{tabular}{|c|c|c|c|c|c|}
\hline \multirow{2}{*}{ Cobertura vegetal } & \multirow{2}{*}{$\begin{array}{c}\text { Doses de } \\
\text { nitrogênio }\left(\mathrm{kg} \mathrm{h}^{-1}\right)\end{array}$} & \multicolumn{2}{|c|}{ Produtividade $\left(\mathrm{sc} \mathrm{ha}^{-1}\right)$} & \multicolumn{2}{|c|}{ Receita bruta (R\$) } \\
\hline & & 2010 & 2011 & 2010 & 2011 \\
\hline \multirow{4}{*}{ Crotalaria juncea } & 0 & 32,85 & 30,59 & $3.718,11$ & $3.625,72$ \\
\hline & 30 & 34,51 & 43,93 & $3.905,78$ & $5.205,99$ \\
\hline & 60 & 35,62 & 42,95 & $4.030,74$ & $5.090,43$ \\
\hline & 90 & 35,42 & 33,30 & $4.008,10$ & $3.946,22$ \\
\hline \multirow{4}{*}{ Milheto } & 0 & 31,62 & 32,27 & $3.578,53$ & $3.824,74$ \\
\hline & 30 & 29,15 & 28,02 & $3.299,38$ & $3.321,03$ \\
\hline & 60 & 30,54 & 37,29 & $3.455,93$ & $4.419,81$ \\
\hline & 90 & 27,00 & 29,55 & $3.055,12$ & $3.502,76$ \\
\hline \multirow{4}{*}{ Guandú } & 0 & 31,17 & 20,59 & $3.527,13$ & $2.440,52$ \\
\hline & 30 & 30,24 & 27,10 & $3.422,45$ & $3.212,39$ \\
\hline & 60 & 32,70 & 30,03 & $3.700,66$ & $3.559,06$ \\
\hline & 90 & 33,63 & 30,96 & $3.805,81$ & $3.669,68$ \\
\hline \multirow{4}{*}{ Crotalaria juncea + milheto } & 0 & 33,25 & 30,37 & $3.762,90$ & $3.599,06$ \\
\hline & 30 & 30,49 & 25,26 & $3.450,27$ & $2.993,62$ \\
\hline & 60 & 35,88 & 29,07 & $4.059,97$ & $3.445,48$ \\
\hline & 90 & 34,11 & 32,65 & $3.860,51$ & $3.870,17$ \\
\hline \multirow{4}{*}{ Guandú + milheto } & 0 & 28,65 & 33,42 & $3.241,85$ & $3.960,54$ \\
\hline & 30 & 29,21 & 30,11 & $3.305,51$ & $3.568,93$ \\
\hline & 60 & 31,32 & 29,15 & $3.544,11$ & $3.455,35$ \\
\hline & 90 & 33,73 & 34,78 & $3.816,66$ & $4.121,53$ \\
\hline \multirow{4}{*}{ Pousio } & 0 & 30,59 & 22,84 & $3.462,06$ & $2.706,70$ \\
\hline & 30 & 31,16 & 30,88 & $3.526,66$ & $3.659,80$ \\
\hline & 60 & 29,01 & 29,93 & $3.282,87$ & $3.546,71$ \\
\hline & 90 & 32,88 & 34,44 & $3.720,46$ & $4.081,53$ \\
\hline
\end{tabular}

Bordin et al. (2003) observaram que a utilização de Crotalaria juncea proporcionou maior produtividade de grãos do feijoeiro, em relação ao milheto e Lab-Lab. O mesmo ocorreu no presente trabalho, no qual as maiores produtividades e, consequentemente, as maiores receitas brutas foram obtidas no tratamento com Crotalaria juncea, nas doses de $30 \mathrm{~kg} \mathrm{ha}^{-1}, 60 \mathrm{~kg} \mathrm{ha}^{-1}$ e $90 \mathrm{~kg} \mathrm{ha}^{-1}$, em 2010. No ano de 2011, observou-se comportamento irregular, no qual as doses de $\mathrm{N}$ não apresentaram as maiores produtividades. De acordo com Rosolem (1996), as condições de resposta ao $\mathrm{N}$ estão relacionadas às características do solo do local de semeadura (cultura anterior, teor de matéria orgânica, textura e irrigação).

Observou-se lucro operacional em todos os tratamentos (Tabela 5), com destaque para a combinação Crotalaria juncea + milheto antecedendo o feijoeiro e adubação com $60 \mathrm{~kg} \mathrm{ha}^{-1}$ de N (R\$ 1.572,72), na safra de 2010, por proporcionar o maior lucro. Em contrapartida, neste mesmo ano, o tratamento com guandú + milheto, com $30 \mathrm{~kg} \mathrm{ha}^{-1}$ de $\mathrm{N}$ em cobertura, apresentou o menor lucro ( $\$$ \$997,69). Na safra 2011, a combinação Crotalaria juncea e $30 \mathrm{~kg} \mathrm{ha}^{-1}$ de $\mathrm{N}$ apresentou o maior lucro ( $\mathrm{R} \$ 2.592,10)$ e Crotalaria juncea + milheto com $30 \mathrm{~kg} \mathrm{ha}^{-1}$ de $\mathrm{N} \mathrm{o}$ menor $(\mathrm{R} \$ 524,10)$.

Verificou-se que, para os preços de $\mathrm{R} \$ 113,17$ e 118,52, por saco de $60 \mathrm{~kg}$ de feijão, para os anos de 2010 e 2011, respectivamente, os tratamentos apresentaram produtividades de equilíbrio abaixo dos valores médios de produtividade obtidos pela cultura, nas condições do estudo, ou seja, a produtividade de equilíbrio, que equivale à produtividade mínima necessária para cobrir os custos, foi menor que a produtividade média obtida, demonstrando, assim, a rentabilidade da cultura em todos os tratamentos, devido ao preço elevado da saca, nestes anos de cultivo (Tabela 6).

Dentre os tratamentos, a utilização de Crotalaria juncea, devido ao elevado preço das sementes, aumentou o valor do custo operacional total, sendo responsável pelas maiores produtividades de equilíbrio. À medida em que aumentam as doses de $\mathrm{N}$, aumentam, também, os valores de COT. Assim, não só o tipo de cobertura vegetal, mas, também, a quantidade de $\mathrm{N}$ interferem nesta variável. 
Tabela 5. Lucro operacional (LO) e índice de lucratividade (IL) obtidos com a cultura do feijão irrigado, em função de coberturas vegetais e doses de nitrogênio (Selvíria, MS, safras de 2010 e 2011).

\begin{tabular}{|c|c|c|c|c|c|}
\hline \multirow{2}{*}{ Cobertura vegetal } & \multirow{2}{*}{$\begin{array}{c}\text { Doses de } \\
\text { nitrogênio }\left(\mathrm{kg} \mathrm{h}^{-1}\right)\end{array}$} & \multicolumn{2}{|c|}{ LO (R\$) } & \multicolumn{2}{|c|}{ IL (\%) } \\
\hline & & 2010 & 2011 & 2010 & 2011 \\
\hline \multirow{4}{*}{ Crotalaria juncea } & 0 & $1.271,34$ & $1.124,27$ & 34,19 & 31,01 \\
\hline & 30 & $1.361,72$ & $2.592,10$ & 34,86 & 49,79 \\
\hline & 60 & $1.399,11$ & $2.375,34$ & 34,71 & 46,66 \\
\hline & 90 & $1.283,34$ & $1.123,50$ & 32,02 & 28,47 \\
\hline \multirow{4}{*}{ Milheto } & 0 & $1.420,52$ & $1.612,04$ & 39,70 & 42,15 \\
\hline & 30 & $1.044,06$ & 995,88 & 31,64 & 29,99 \\
\hline & 60 & $1.113,05$ & $1.993,46$ & 32,21 & 45,10 \\
\hline & 90 & 619,11 & 968,79 & 20,26 & 27,66 \\
\hline \multirow{4}{*}{ Guandú } & 0 & $1.368,03$ & 226,73 & 38,79 & 9,29 \\
\hline & 30 & $1.166,04$ & 886,15 & 34,07 & 27,59 \\
\hline & 60 & $1.356,68$ & $1.131,62$ & 36,66 & 31,80 \\
\hline & 90 & $1.368,71$ & $1.134,61$ & 35,96 & 30,92 \\
\hline \multirow{4}{*}{ Crotalaria juncea + milheto } & 0 & $1.460,51$ & $1.241,98$ & 38,81 & 34,51 \\
\hline & 30 & $1.050,58$ & 524,10 & 30,45 & 17,51 \\
\hline & 60 & $1.572,72$ & 874,75 & 38,74 & 25,39 \\
\hline & 90 & $1.280,12$ & $1.191,82$ & 33,16 & 30,80 \\
\hline \multirow{4}{*}{ Guandú + milheto } & 0 & $1.031,34$ & $1.695,34$ & 31,81 & 42,81 \\
\hline & 30 & 997,69 & $1.191,29$ & 30,18 & 33,38 \\
\hline & 60 & $1.148,72$ & 976,50 & 32,41 & 28,26 \\
\hline & 90 & $1.328,14$ & $1.535,06$ & 34,80 & 37,24 \\
\hline \multirow{4}{*}{ Pousio } & 0 & $1.408,10$ & 598,06 & 40,67 & 22,10 \\
\hline & 30 & $1.375,41$ & $1.438,71$ & 39,00 & 39,31 \\
\hline & 60 & $1.044,05$ & $1.224,42$ & 31,80 & 34,52 \\
\hline & 90 & $1.388,51$ & $1.651,62$ & 37,32 & 40,47 \\
\hline
\end{tabular}

Tabela 6. Produtividade e preço de equilíbrio obtidos com a cultura do feijão irrigado, em função de coberturas vegetais e doses de nitrogênio (Selvíria, MS, safras de 2010 e 2011).

\begin{tabular}{|c|c|c|c|c|c|}
\hline \multirow[t]{2}{*}{ Cobertura vegetal } & \multirow{2}{*}{$\begin{array}{c}\text { Doses de } \\
\text { nitrogênio }\left(\mathrm{kg} \mathrm{h}^{-1}\right)\end{array}$} & \multicolumn{2}{|c|}{$\begin{array}{l}\text { Produtividade de equilíbrio } \\
\left(\mathrm{sc} \mathrm{ha}^{-1}\right)\end{array}$} & \multicolumn{2}{|c|}{$\begin{array}{c}\text { Preço de equilíbrio } \\
\left(\mathrm{R} \$ \mathrm{sc}^{-1}\right)\end{array}$} \\
\hline & & 2010 & 2011 & 2010 & 2011 \\
\hline \multirow{4}{*}{ Crotalaria juncea } & 0 & 21,62 & 21,11 & 74,47 & 81,77 \\
\hline & 30 & 22,48 & 22,05 & 73,71 & 59,51 \\
\hline & 60 & 23,25 & 22,91 & 73,89 & 63,22 \\
\hline & 90 & 24,08 & 23,82 & 76,93 & 84,78 \\
\hline \multirow{4}{*}{ Milheto } & 0 & 19,07 & 18,67 & 68,25 & 68,57 \\
\hline & 30 & 19,93 & 19,62 & 77,36 & 82,98 \\
\hline & 60 & 20,70 & 20,47 & 76,72 & 65,06 \\
\hline & 90 & 21,53 & 21,38 & 90,24 & 85,74 \\
\hline \multirow{4}{*}{ Guandú } & 0 & 19,08 & 18,68 & 69,28 & 107,51 \\
\hline & 30 & 19,94 & 19,63 & 74,61 & 85,83 \\
\hline & 60 & 20,71 & 20,48 & 71,68 & 80,84 \\
\hline & 90 & 21,53 & 21,39 & 72,47 & 81,88 \\
\hline \multirow{4}{*}{ Crotalaria juncea + milheto } & 0 & 20,34 & 19,89 & 69,24 & 77,62 \\
\hline & 30 & 21,20 & 20,84 & 78,71 & 97,77 \\
\hline & 60 & 21,98 & 21,69 & 69,33 & 88,43 \\
\hline & 90 & 22,80 & 22,60 & 75,64 & 82,02 \\
\hline \multirow{4}{*}{ Guandú + milheto } & 0 & 19,53 & 19,11 & 77,17 & 67,79 \\
\hline & 30 & 20,39 & 20,06 & 79,01 & 78,96 \\
\hline & 60 & 21,17 & 20,92 & 76,49 & 85,03 \\
\hline & 90 & 21,99 & 21,82 & 73,79 & 74,38 \\
\hline \multirow{4}{*}{ Pousio } & 0 & 18,15 & 17,79 & 67,14 & 92,33 \\
\hline & 30 & 19,01 & 18,74 & 69,03 & 71,93 \\
\hline & 60 & 19,78 & 19,59 & 77,18 & 77,60 \\
\hline & 90 & 20,61 & 20,50 & 70,93 & 70,56 \\
\hline
\end{tabular}


O preço de equilíbrio é influenciado pelo COT e pela produtividade. Desta maneira, quanto maior a produtividade, menor o preço de equilíbrio. Na safra de 2010, de maneira geral, os tratamentos apresentaram comportamento semelhante, sendo o maior preço de equilíbrio proporcionado pelo tratamento com milheto (dose de $90 \mathrm{~kg} \mathrm{ha}^{-1}$ ) e o menor o resultante do pousio (sem aplicação de adubação nitrogenada). Já na safra de 2011, os menores preços resultaram dos tratamentos com Crotalaria juncea (doses de $30 \mathrm{~kg} \mathrm{ha}^{-1}$ e $60 \mathrm{~kg} \mathrm{ha}^{-1}$ ), sendo o maior observado no tratamento com guandú (sem aplicação de adubação nitrogenada).

\section{CONCLUSÕES}

1. O uso de Crotalaria juncea, como cobertura vegetal do solo, proporcionou os maiores valores de produtividade de grãos, receita bruta e custo operacional total, nos dois anos agrícolas.

2. O maior lucro operacional, na safra de 2010, e, consequentemente, os melhores índices de lucratividade foram obtidos pelo uso de guandú, como cobertura do solo, e, em 2011, pelo uso de Crotalaria juncea.

3. As maiores produtividades de equilíbrio foram obtidas pelo uso de Crotalaria juncea, devido ao preço da semente.

4. O aumento nas doses de nitrogênio resultou em tendência de aumento na produtividade e contribuiu para o aumento no preço de equilíbrio.

\section{REFERÊNCIAS}

AMADO, T. J. C; MIELNICZUK, J.; AITA C. Recomendação de adubação nitrogenada para o milho no RS e SC adaptada ao uso de culturas de cobertura do solo, sob sistema de plantio direto. Revista Brasileira de Ciência do Solo, Viçosa, v. 26, n. 2, p. 241-248, 2002.

AMBROSANO, J. E. et al. Feijão. In: RAIJ, B. V. et al. Recomendação de adubação e calagem para o Estado de São Paulo. 2. ed. Campinas: IAC, 1996. p. 194-195.

ANDRIOLI, I. et al. Produção de milho em plantio direto com adubação nitrogenada e cobertura do solo na pré-safra. Revista Brasileira de Ciência do Solo, Viçosa, v. 32, n. 3, p. 1691-1698, 2008.

ARF, O. et al. Efeito da rotação de culturas, adubação verde e nitrogenada sobre o rendimento do feijão. Pesquisa Agropecuária Brasileira, Brasília, DF, v. 34, n. 11, p. 20292036, 1999.
BORDIN, L.; FARINELLI, R.; GUIDO, F. Sucessão de cultivo de feijão-arroz com doses de adubação nitrogenada após adubação verde, em semeadura direta. Bragantia, Campinas, v. 62, n. 3, p. 417-428, 2003.

CANTARELla, H.; RAIJ, B. V.; CAMARGO, C. Cereais. In: RAIJ, B. V. et al. Recomendações de calagem e adubação para o Estado de São Paulo. Campinas: IAC, 1997. (Boletim técnico, 100).

CREPALDI S. A. Contabilidade rural: uma abordagem decisorial. 2. ed. São Paulo: Atlas, 1998.

EMPRESA BRASILEIRA DE PESQUISA AGROPECUÁRIA (Embrapa). Centro Nacional de Pesquisa de Solos. Sistema brasileiro de classificação de solos. 2. ed. Rio de Janeiro: Embrapa Solos, 2006.

FUNDAÇÃO GETÚLIO VARGAS (FGV). IGP-DI. 2012. Disponível em: <http://portal.fgv.br/>. Acesso em: 30 jul. 2012.

INSTITUTO DE ECONOMIA AGRÍCOLA (IEA). Preços. 2012. Disponível em: <http://ciagri.iea.sp.gov. $\mathrm{br} / \mathrm{bancoiea} / \mathrm{precos}$ medios.aspx? $\mathrm{cod} \_\mathrm{sis}=2>$. Acesso em: 30 jul. 2012.

LEMOS, L. B.; FERREIRA, D. C.; FARINELLI, R. Desempenho agronômico, nutricional e tecnológico de cultivares de feijoeiro adubados com nitrogênio em cobertura no sistema de plantio direto. In: CONGRESSO NACIONAL DE PESQUISA DE FEIJÃO, 9., 2008. Campinas. Anais... Campinas: IAC, 2008. p. 1400-1403.

MALAVOLTA. E. Adubos nitrogenados. In: MALAVOLTA. E. $A B C$ da adubação. 4. ed. São Paulo: Agronômica Ceres, 1979. p. 25-39.

MARTIN, N. B. et al. Sistema "CUSTAGRI": sistema integrado de custo agropecuário. Informações Econômicas, Piracicaba, v. 28, n. 1, p. 4-7, 1998.

OLIVEIRA, T. K.; CARVALHO, G. J.; MORAES, R. N. S. Plantas de cobertura e seus efeitos sobre o feijoeiro em plantio direto. Pesquisa Agropecuária Brasileira, Brasília, DF, v. 37, n. 8, p. 1079-1087, 2002.

RAIJ, B. V.; QUAGGIO, J. A. Métodos de análises de solo para fins de fertilidade. Boletim Técnico do Instituto Agronômico, Campinas, v. 81, n. 1, p. 1-31, 1983.

ROSOLEM, C. A. Calagem e adubação mineral. In: ARAÚJO, R. S. et al. (Coords.). Cultura do feijoeiro comum no Brasil. Piracicaba: Potafos, 1996. p. 353-390.

SORATTO, R. P. Resposta do feijoeiro ao preparo do solo, manejo de água e parcelamento da adubação nitrogenada. 2002. 72 f. Dissertação (Mestrado em Sistemas de Produção) - Faculdade de Engenharia de Ilha Solteira, Universidade Estadual Paulista, Ilha Solteira, 2002. 